\title{
Conselhos de saúde, comissões intergestores e grupos de interesses no Sistema Único de Saúde (SUS)
}

\author{
Health councils, intergovernmental commissions, \\ and interest groups in the Unified Health \\ System (SUS)
}

José Mendes Ribei ro 1

\footnotetext{
1 Departamento de Ciências Sociais, Escola Nacional de Saúde Pública, Fundação Oswaldo Cruz. Rua Leopoldo Bulhões 1480, Rio de Janeiro, RJ 21041-210, Brasil.
}

Abstract Health councils have devel oped in Brazil in keeping with arrangements under the 1988 Constitution, and the logi c of their political consensus has expanded among interest groups relevant to public policy. Collegiate bodies, such as intergovernmental commissions, represent an extension of that logic to executive relationships and also express political intermediation by expertise, following the tradition of the European Welfare State. The state technical bureaucracy has thus devel oped a remarkable role in policy-making and in State-level modeling of interest groups. This article argues that such collegiate bodies should be analyzed through State action and defines two models for health councils. One, the vocal political model, is characterized by a prevalence of outspoken denunciation and an overload of demands on the political agenda. The other, the consensus model, expresses self-limitation amongst interest groups in drafting demands. These models are not hierarchically fixed and are usually linked to the political platforms of interest groups participating in the coll egi ate bodies.

Key words Health Councils; Health Systems; Health Policy; Public Health

Resumo Os consel hos de saú de desenvolveram-se no Brasil em decorrência dos arranjos constituci onais de 1988 e expandi ram a sua lógica de pactuação política entre grupos de interesses relevantes para a política pública. Organismos colegiados como as comissões intergestores repre sentam a extensão desta lógi ca para as relações intergovernamentai s e expressam também a intermedi ação da política pela técnica, acompanhando a tradição do estado de bem-estar europeu. Neste contexto, a tecnoburocracia de estado assume papel rel evante no processo de tomada de decisões e na própria model agem que o Estado processa para a atuação dos grupos de interesses. $\mathrm{O}$ artigo propõe o estudo destes organismos col egiados a partir de um enfoque centrado no Estado e que define dois model os de consel hos de saúde. Um deles, o de vocalização política, caracteriza-se pelo predomínio das denúncias e por sobrecarga de demanda sobre a agenda política. Outro, o de pactuação, expressa o predomínio dos acordos entre os grupos de interesses e a autol imitação na formulação de demandas. Estes model os não são hi erarquizados e muitas vezes expressam o próprio i deário políti co de alguns dos grupos partici pantes dos colegiados. Palavras-chave Consel hos de Saúde; Si stemas de Saúde; Política de Saúde; Saúde Pública 


\section{Introdução}

A reforma sanitária brasileira, impulsionada pela VIII Conferência Nacional de Saúde (1986), representou uma matriz do pensamento político de esquerda em torno da qual formou-se uma ampla coalizão de interesses, materializados na Assembléia Nacional Constituinte (1988), em um contexto de reformas democráticas voltadas a redefinir as relações entre Estado e sociedade civil após o longo período de ditadura militar. 0 modelo proposto para a saúde, de participação societária, o qual pode ser observado no próprio conjunto do capítulo da Seguridade Social da Constituição Federal, destinava-se a ser retraduzido para as demais políticas públicas. A plena regulamentação do Sistema Único de Saúde (SUS) demorou pelo menos até 1990 (com a aprovação das Leis 8.080 e 8.142) e sofreu vetos presidenciais importantes em diversos artigos, especialmente no que se refere aos mecanismos de transferência de recursos financeiros.

O SUS esteve, desde o início, alicerçado em três pontos: a universalização da assistência, o controle social e a normatização técnica das alocações financeiras. Destes, apenas os dois primeiros pontos podem ser considerados como avanços percebidos com maior consistência. A questão do financiamento do sistema esbarra nas oscilações dos gastos nas três esferas governamentais, em questionamentos jurídicos quanto ao fluxo das transferências, alvo de investigações pelo Ministério Público Federal (Melamed \& Ribeiro, 1995), e na definição mais clara do perfil de necessidades sociais em termos de cobertura e modelo de assistência. A universalização da assistência é perceptível através do acesso proporcionado a clientelas não previdenciárias junto a hospitais e ambulatórios do ex-Inamps ou conveniados e da recente ampliação das redes munici pais de saúde. A questão do controle social, comumente referida à formação e atuação dos conselhos de saúde, tem se mostrado, por outro lado, a principal inovação política do SUS e seu conceito básico de pactuação política entre grupos de interesses tem penetrado, inclusive, as próprias relações intergovernamentais, especialmente a partir da criação das comissões intergestores bipartite ( $\mathrm{CIB}$ ) e tripartite (CIT). Estes espaços públicos de conflito e pactuação política são usual mente tratados em abordagens acerca da ação coletiva, como na teoria pluralista, ou sobre o neocorporativismo; a adaptação do estado capitalista contemporâneo ao conflito entre as lógicas da acumulação e da eqüidade remete-se à temática do estado de bem-estar social e crítica liberal.
Neste artigo buscamos estabelecer uma análise preliminar acerca das possibilidades concretas de consolidação de inovações políticas resultantes da crescente ação dos conseIhos de saúde no plano da política setorial. Pretendemos, assim, desenvolver o tema da participação social pela compreensão das margens efetivas de atuação de sujeitos coletivos e individuais perante as estruturas econômicas, políticas e sociais vigentes.

\section{Sujeitos, estruturas de determinação} e dilemas da reflexão sociológica

Existe vasta literatura que trata da adequação de elementos da teoria marxista às novas contingências políticas e sociais. De certa forma, os trabalhos mais relevantes buscam enfatizar o papel dos sujeitos perante as estruturas sócio-econômicas; relativizar a determinação da base estrutural econômica da sociedade e enfatizar o papel da superestrutura na conformação da ordem social. Os estudos são observados dentro de uma definição mais claramente marxista ou tomando esta tradição apenas como referência geral. No primeiro caso, ressaltese Wright et al. (1993), que apresentam o conceito de materialismo histórico fraco e a substituição da idéia de determinação por penetração causal relacionada aos fatos históricos. Entretanto, um conjunto importante de formulações busca preservar a crítica ao pensamento liberal clássico e suas vertentes elitistas e utilitaristas, reservando ao marxismo o caráter menos normativo, de referência teórica relevante. Neste contexto, Elster (1989; 1994) propugna uma redução analítica ao plano do indivíduo e de seus interesses como método de explicação para a instituição das normas sociais e dos mecanismos de coesão social (individualismo metodológico, que freqüenta a tradição weberiana), apontando fatores estruturais que permeiam os conflitos de interesses no plano dos "jogos" e práticas cotidianas. Souza-Santos (1995), ao assinalar a crise dos paradigmas centrais das ciências sociais, critica os enfoques que enfatizam a separação entre o Estado e a sociedade civil, dando ênfase aos papéis que os indivíduos desempenham em suas comunidades de interesses e a absorção no plano societário de tarefas de amparo social ("sociedade-providência"). Embora a tese da dissolução do Estado na sociedade civil pareça atraente, pelo que capta de movimentos internos à sociedade, a realidade instiga uma observação contrária - uma forte tendência à autonomização do Estado capitalista contemporâneo e de 
sua tecnoestrutura burocrática. Entretanto, o debate político da esquerda tem enfatizado o papel de elementos como vida associativa, normas e val ores sociais, escolha racional, em contraste tanto com a determinação social unívoca pela infra-estrutura econômica, quanto com o seu oposto - a imagem de caos e indeterminação absoluta. O chamamento do Estado aos grupos de interesses para atuarem em organismos de gestão de políticas públicas também estimula análises que apontam a dissolução da oposição assinalada entre Estado e sociedade civil. Por outro lado, lembramos que teóricos do neocorporativismo (Schmitter, 1979; Offe, 1989) apontaram o papel relevante do Estado na própria estruturação da ação destes grupos de interesses societários na esfera da gestão pública.

A aplicação do termo corporativismo, destituído de suas conotações autoritárias relacionadas ao fascismo italiano e ao Estado Novo de Vargas, por exemplo, em estudos acerca de políticas, interessa pelo que diferencia com relação à teoria pluralista dos grupos de pressão distribuídos por mercados. Para Schmitter (1979), o que caracteriza o novo corporativismo é justamente o papel do Estado em estruturar interlocutores societários, conferindo a eles certa margem de acesso a decisões alocativas, em troca do seguimento a determinadas normas de conduta por parte dos grupos de interesse. Como assinala, "corporatism can be defined as a system of interest representation in which the constituent units are organized into a limited number of singular, compulsory, noncompetitive, hierarchically ordered and functionally differentiated categories, recognized or licensed (if not created) by thestate and granted a deliberate representational monopoly within their respective categories in exchange for observing certain controls on their selection of leaders and articulations of demands and supports" (1979:13). Naturalmente, o autor flexibiliza esta definição para dar conta de matrizes mais centradas no Estado ou societárias, conforme os casos estudados.

As relações entre sindicatos e associações empresariais, entre outras, e o Estado também pertencem à temática da ação coletiva e da ordem social. Em estudo também clássico, Offe (1989:223-268) assinala, adicionando novas variáveis, que a organização de interesses “é sempre resultado do interesse mais a oportunidade mais o status institucional (...) É determinada por parâmetros ideológicos, econômicos e políticos" (Offe, 1989:225). Observa, desse modo, a dinâmica sócio-política do estado de bemestar, com ênfase no seu papel de atribuição de status público aos grupos de interesses e de definição de áreas de conflitos e implementação de políticas.

Nestas abordagens, o Estado ocupa o centro do processo de formulação de políticas, o que enfraquece, a nosso ver, as teses que apontam sua dissolução na sociedade civil, seja através do mercado de bens e serviços, ou pela dinâmica autônoma dos grupos de interesses societários. Lembramos que a polarização política promovida pelos neoconservadores, mais intensa e sistemática nos anos 80-90, aponta mais para um redirecionamento das ações do Estado e de seu ordenamento administrativo em torno da gestão da economia ("ajustes estruturais"), do que para uma real e efetiva redução de seus poderes normativos e alocativos.

Desse modo, parecem mais consistentes reflexões como as de Habermas (1968; 1994), relativas ao estado de bem-estar social, quando assinala a tendência da ideologia da troca livre ser superada por um programa substitutivo orientado pelas conseqüências sociais e de este estado compensar as disfunções do livre intercâmbio. Neste enfoque, as políticas públicas compõem, de modo estrutural, a agenda pública. Este entendimento assemelha-se ao de Offe (1984), que aponta este estado como estrategicamente voltado a viabilizar a força de trabaIho como mercadoria e a operar a substituição da política pela intervenção técnica. Desta forma, as políticas públicas respondem a estratégias redistributivas sancionadas eleitoralmente, à ação dos grupos de interesses e aos mecanismos de pactuação desenvolvidos. Este arranjo entra em crise, no cenário europeu, na década de 70, e mais intensamente nos anos 80 , tensionado pelo pensamento neoconservador, que busca retomar a ideologia da livre troca do século XIX. A crise do estado de bem-estar penetra o debate brasileiro, no qual as soluções propugnadas naquele cenário são apresentadas a um país que não experimentou em sua plenitude a aplicação integral do programa substitutivo do capitalismo. Com a crise são questionados itens substantivos dos pactos neocorporativos, como a ampliação dos gastos públicos e a representatividade política dos grupos de interesses. Para Offe (1989), esta crise decorre da degeneração do modelo neocorporativo, desenvolvido sobre o enfraquecimento da representação político-territorial, e pode ser explicada por alterações nas bases morais da sociedade e na ação seletiva dos indivíduos perante as diferentes políticas. Esta ação extrapola a simples atitude de adesão ou negação completa ao programa redistributivo do Esta- 
do, tornando útil modelos explicativos como os de Elster (1989; 1994), que evidenciam uma tendência atual nas ciências sociais ao ecletismo como forma de fugir a modelos explicativos funcionalistas.

\section{Conseqüências para o estudo das políticas de saúde no Brasil}

As referências às relações entre estruturas e agentes na conformação da ordem social influenciam o tratamento analítico aqui pretendido. As políticas públicas originam clientelas dependentes dos bens produzidos e incorporam grupos e indivíduos em instâncias decisórias centradas no Estado, além de interferirem na dinâmica de legitimação do capitalismo avançado. Cumpre definir a relevância da ação individual, tão cara ao pensamento liberal, sem descuidar dos fatores estruturais que limitam e modelam atitudes e aspirações, como destaca a tradição marxista.

Partimos do pressuposto de que as políticas, além de produzirem clientelas e esferas de decisão, promovem a emergência de elites relevantes, que abrangem desde segmentos da burocracia de Estado até representantes societários com acessos privilegiados em troca da aceitação de determinadas regras de conduta e convívio. Como conseqüência desta institucionalização dos conflitos, o Estado ocupa o centro do processo de formulação e decisões para as diferentes políticas, incluindo-se as de saúde e as inovações observadas no caso brasileiro, como os consel hos de saúde e outros órgãos colegiados.

Para uma abordagem mais adequada das políticas públicas ressaltamos, portanto, a importância dos papéis da burocracia técnica do Estado e de tomadores de decisão associados a grupos de interesses. No Brasil reproduz-se, a grosso modo, a tendência de este Estado ocupar o centro da mediação social, apesar de mudanças pretendidas no perfil da ação: decisões econômicas ligadas a taxas de câmbio ou juros demonstram a distância objetiva que a realidade impõe aos que o imaginam dissolvido em laços societários difusos.

No que se refere à política de saúde no Brasil, especialmente após a Constituição de 1988, observa-se que o Sistema Único de Saúde (SUS) institucionaliza, através dos Conselhos de Saúde, a ação dos grupos de interesses e confere ao pacto local e nacional funções de difusão de informações, vocalização política de demandas sociais, estabelecimento de parâmetros para a gestão do sistema e promoção de seu equilíbrio.
A questão dos conselhos de saúde no caso do SUS, no Brasil, parece um terreno fértil para estudos a partir de tais abordagens teóricas. Os consel hos implicam a participação de grupos sociais organizados, como sindicatos, associações de moradores, igrejas, junto a representantes diretos do executivo, como secretários de saúde e técnicos graduados. Esta participação atende a uma normatização pelo Estado, que define seus contornos, escopo de decisões, participantes etc. Desta forma, a nosso ver, duas temáticas relevantes para a pesquisa social emergem.

Uma delas, que não será abordada diretamente neste artigo e que será remetida a outro momento (Ribeiro, 1996), refere-se à formação da tecnoestrutura de Estado que participa da elaboração de problemas e de soluções no processo de tomada de decisões na política de saúde e como ela responde à entrada em cena de grupos de interesses emergentes ao processo decisório através dos conselhos de saúde. Esta questão permite uma abordagem teórica diversificada. De forma resumida, podemos assinalar que o desenvolvimento tecnológico observado no capitalismo implicou uma incorporação da ciência e da técnica no cotidiano social e de suas organizações públicas e privadas. Em seu estudo, Ianni (1986) cita Galbraith e seu conhecido conceito de tecnoestrutura, elaborado ao estudar as transformações no interior da empresa capitalista, designada como o arcabouço formado por especialistas que penetram os espaços de decisão e operam uma substituição paulatina do patrão tradicional. Para Ianni (1986), no Brasil desenvolveu-se uma tecnoestrutura estatal, especialmente a partir da Revolução de 1930, centrada em tarefas de planejamento macroeconômico e gerência de grandes empresas industriais estatais, a qual é formada por um corpo de especialistas que influi decisivamente no processo de tomada de decisões. Este conceito nos parece adequado para a análise da formação da burocracia pública no Brasil, para além do planejamento econômico, e envolvida com a política de saúde. A literatura no setor expressa a importância dos especialistas no ordenamento das ações através da lógica da programação em saúde (Mendes-Gonçalves et al.,1990), da compreensão do processo de trabalho de grupos profissionais estratégicos para o desenvolvimento destas políticas, como no caso dos médicos (Schraiber, 1993), pela sua organização em movimentos políticos (SouzaCampos, 1988) ou na forma como técnicos conformam modelos de atenção (Merhy, 1992).

A outra questão, objeto deste artigo, referese ao alcance da atuação dos conselhos e pers- 
pectivas para o desenvolvimento de arranjos de caráter neocorporativo na estruturação dos conflitos decisórios no âmbito da política de saúde. Os limites e as possibilidades de abordagens que recorrem a este model o para estudar este processo decisório no Brasil no contexto da reforma sanitária têm si do apontados por alguns autores (Vaitsman, 1989; Ribeiro, 1993).

Estado, conselhos de saúde e grupos de interesses

O final da década de 70 e, mais marcadamente, os anos 80 caracterizaram-se no Brasil pelo processo de transição política do regime militar para uma democracia representativa ("distensão"; “abertura política”). As forças políticas de oposição e de esquerda passaram a participar do jogo eleitoral e a interferir na dinâmica parlamentar. Neste contexto, partidos, sindicatos, associações estudantis, eclesiásticos, entre outros, envolveram-se mais diretamente na formulação e tomada de decisão em políticas públicas. Uma constante observada na ação destes grupos foi a defesa de um Estado redistributivo e aberto a influências societárias enquanto uma matriz específica do regime democrático. De certa forma, o ideário social-democrata foi absorvido pela esquerda política brasileira, juntamente com sua agenda típica dos anos 70, em contraponto ao ideário liberal de descentralização das decisões alocativas para a esfera do mercado. O pensamento político de esquerda advogou a defesa do Estado formulador de políticas públicas mais abrangentes e inclusivas, com a incorporação de grupos organizados, conseqüentemente tornando público o processo decisório. A própria movimentação social e político-partidária em torno da Assembléia Nacional Constituinte (ANC) serve a esta constatação. A ANC de 1988 expressou a convergência destas estratégias em torno de propostas de adequação do Estado brasileiro ao quadro político que emergiu do longo processo de desmonte da ditadura da elite militar.

No setor saúde, este ideário político foi materializado nos preceitos básicos do Sistema Único de Saúde (SUS), regulamentado em legislação ordinária em 1990 (Leis 8.080 e 8.142), e implementado através de normas operacionais (Ribeiro, 1994). Este arcabouço institucional foi marcado por inúmeras inovações políticas desenvolvidas em meio a uma conjuntura sanitária conhecida como "caos da saúde". O sugerido fracasso do SUS pode ser depreendido pelo noticiário jornalístico, pelos eventos observados nas grandes cidades do País em termos de racionamento da oferta de serviços e pelas pesquisas de opinião pública nas quais o item saúde é freqüentemente apontado como um dos principais problemas sociais. Como explicações para a deslegitimação do SUS, para além dos déficits regulatórios e racionamentos observados na oferta de serviços, podemos apontar, também, a atuação de grupos relevantes, como facções políticas conservadoras e associações empresariais do setor, a migração de setores sindicais para os segurossaúde que se multiplicam pelo País (Costa, 1994) e a auto-exclusão de camadas médias da sociedade do sistema público (Faveret Filho et al., 1989). O contexto de "caos na saúde" é mais evidente nos grandes centros urbanos, o que obscurece a amplitude dos serviços oferecidos especialmente em termos de atenção ambulatorial em todo o País, o acesso amplo a procedimentos de alto custo e de alta complexidade e a própria extensão da oferta de serviços hospitalares e especializados a pequenas e médias cidades. Uma análise mais precisa da questão do "caos sanitário" deve considerar um maior número de variáveis, para além do acesso a serviços hospitalares e ambulatoriais em alguns centros urbanos, e decompor a assistência por itens de atenção, por exemplo.

Quanto à questão do controle social, observamo-la sob a luz da expansão de instâncias decisórias no SUS, tanto em termos de participação societária, como de outros organismos colegiados entre esferas do executivo. Daí emergem duas importantes inovações políticas no quadro sanitário dos anos 90: os conselhos de saúde e as comissões paritárias de secretários de saúde.

Os conselhos de saúde são propugnados pela Constituição Federal e regulamentados na legislação ordinária, tendo se tornado uma realidade na política setorial (Carvalho, 1995). A Constituição Federal define na seção II, artigo 198, que o SUS seja organizado de acordo com a "participação da comunidade". Esta participação é regulamentada pela Lei 8.142, de 28 de dezembro de 1990, que designa a conferência de saúde "com representação dos vários segmentos sociais", a reunir-se a cada quatro anos, e o consel ho de saúde em cada esfera de governo, como instâncias colegiadas participantes da gestão do sistema. A mesma lei, no artigo 1o, parágrafo 2o, define: “O conselho de saúde, em caráter permanente e deliberativo, órgão colegiado composto por representantes do governo, prestadores de serviço, profissionais de saúde e usuários, atua na formulação de estratégias e no controle da execução da política de 
saúde na instância correspondente, inclusive nos aspectos econômicos e financeiros, cujas decisões serão homologadas pelo chefe do poder legalmente constituído em cada esfera de governo". Nesta lei é ainda atribuído status público ao Conselho Nacional de Secretários de Saúde (Conass) e ao Conselho Nacional de Secretários Municipais de Saúde (Conasems), por meio da representação no conselho nacional de saúde, e define-se o caráter paritário destes conselhos.

A proliferação de órgãos colegiados de pactuação entre atores relevantes ao SUS expressa duas tendências evidentes: a participação societária em políticas de Estado e as alianças políticas intraburocráticas mediadas pelo discurso técnico. Em outras palavras, a definição pelo Estado das estruturas decisórias e a intermediação da política pela técnica. Isto produz uma expectativa de convergência dos grupos de interesses em torno de uma tecnoburocracia renovada e autônoma capaz de estruturar demandas, conflitos e projetos nas esferas do Estado e da sociedade civil.

O Sistema Ú nico de Saúde (SUS) representaria, enquanto modelo de política setorial, se utilizarmos a matriz analítica de Offe (1989), a hegemonia do padrão redistributivo do Estado no âmbito da articulação recíproca, não evolutiva, entre a economia de mercado, a democracia política e o estado de bem-estar social. O controle social sobre o Estado representa, na verdade, o desenvolvimento de uma elite societária que se articula com a burocracia de Estado e o estabelecimento de pactos nas diferentes esferas governamentais entre os grupos de interesses relevantes à política setorial.

Um estudo adequado acerca destes arranjos institucionais deve determinar o grau de adesão destes grupos aos organismos assim estabelecidos e o volume de decisões adotadas e associadas a eventos real mente implementados a partir destas decisões. Para que haja uma efetiva estabilização da política pública deve haver uma atração dos grupos expressivos no mercado para o contexto destas políticas e o estabelecimento de acordos substantivos. Esta temática é bem desenvolvida na literatura acerca do neocorporativismo, sistematizada com base em Schmitter (1979), como citado, ao fixar sua distinção com relação à teoria pluralista, a qual tende a obscurecer o papel de agências do Estado na conformação da ação dos grupos de interesses.
Tendências para o desenvolvimento dos conselhos de saúde no Brasil

Analisamos o funcionamento e a agenda dos conselhos de saúde no Brasil valendo-nos, fundamentalmente, da nossa experiência e observação destes organismos e da consulta a atas de reuniões. Em termos de observação direta, remetemo-nos a participações como palestrante, consultor, observador e representante setorial. No caso de outros organismos colegiados, consultaram-se atas e documentos institucionais, além da observação direta, que resulta da atuação como assessor técnico do Conselho Estadual de Secretários Municipais de Saúde do Rio de Janeiro (Cosems/RJ) na comissão intergestores bipartite do Rio de Janeiro (CIB/RJ ). O Rio de Janeiro foi, dessa maneira, a região observada mais detalhadamente.

O modelo proposto visa a orientar estudos de caso ou comparados para melhor compreensão da dinâmica decisória destes organismos. O recurso à experiência pessoal do autor é consi derado em função de sua amplitude e permite uma sistematização que, acreditamos, supera o simples registro de impressões genéricas. Os conflitos entre indivíduos e grupos internos nos consel hos e conferências de saúde estimula a reflexão dos participantes e a elaboração de discursos sistemáticos. Desta forma, a observação efetuada é ativa e resulta de interações com o ambiente estudado. As conferências de saúde proporcionam interlocuções entre agentes e grupos diversos, como secretários de saúde, sindicatos, partidos políticos, associações de moradores ou grupos de risco específicos, igrejas, entidades filantrópicas, entre outros, através de mecanismos formalizados de representação política e de interesses organizados.

A participação em conferências ocorreu de duas maneiras: como palestrante/ debatedor de itens de pauta e como representante com direito a voto.

Como palestrantes, participamos das Conferências de Saúde de Piraí/RJ (1993; 1995), Arraial do Cabo/RJ (1994), Petrópolis/RJ (1994), Niterói/RJ (1996), Teresópolis/ RJ (1996) eltaguaí/ RJ (1996), assim como da Conferência Nacional de Saúde em Brasília/ DF (1996). Como representantes setoriais, destacamos a Conferência Distrital da AP3.2 do Rio de Janeiro/RJ (1993) e a Conferência Municipal do Rio de Janeiro/ RJ (1993).

Na qualidade de consultor do Ministério da Saúde no período de 1993-94, foram efetuadas visitas a reuniões ordinárias de conselhos de saúde e contatos com conselheiros. Observa- 
ções sistematizadas podem ser encontradas em relatórios de pesquisa enviados à Secretaria de Assistência à Saúde/ MS. Destas visitas, destacamos os Conselhos Municipais de Saúde de Angra dos Reis, Volta Redonda, Arraial do Cabo e Itatiaia, todos no Estado do Rio de Janeiro.

No caso do Conselho Nacional de Saúde, estudamos registros em atas do período de 1617/11/1994 a 07-08/02/1996, totalizando 12 reuniões. Ainda no plano nacional, analisamos também as atas de reuniões da comissão intergestores tripartite, formada por representantes das três esferas de governo, no período de 1993 a 1999.

As impressões acerca de interesses de secretários de saúde provêm da experiência como assessor técnico do Cosems/RJ e da participação, nesta condição, da CIB/RJ no período 1994-1996 e como observador em reuniões da CIT.

Quanto ao tratamento metodológico oferecido a este universo variado de fontes e impressões, optamos por trabal har com o processo de definição de agendas. Assim caracterizamos as ações individuais, de grupos e de autoridades governamentais perante os itens tornados relevantes para a política de saúde nos organismos colegiados. Observamos a dinâmica dos conflitos e os mecanismos de constituição de consensos e rupturas, que permitiram estabelecer, em caráter preliminar, os modelos discutidos adiante. No caso das comissões intergestores, formadas por esferas governamentais, evitamos maiores conclusões em função de seu caráter incipiente, mas ressal tamos os pontos de contato com os conselhos de saúde, aos quais estão normativamente subordinadas, e o que representam de expansão da lógica de pactuação que se dissemina pelo setor da saúde nos anos 90 .

Como resultado deste estudo, apontamos dois modelos básicos de funcionamento para os consel hos de saúde. Um deles, fundado na vocalização política dos grupos de interesses representados que promovem uma sobrecarga de demandas e processamento extra-institucional dos temas da agenda; o outro, de pactuação, fundamenta-se na prática mais constante de acordos políticos entre estes grupos. Estes modelos destinam-se apenas a facilitar linhas de investigação e podem alternar-se na mesma localidade geográfica enquanto dominantes. Além disso, podem representar pontos de vista políticos de tais grupos.

A construção destes modelos resulta da própria metodologia adotada. Ao privilegiar interações entre agentes e a formação de agen- das, a observação do Conselho Nacional de Saúde demonstra seu caráter de pactuação decorrente do alto grau de estruturação de sua agenda. Os temas aí tratados se mostraram abrangentes, com nítido predomínio de diagnósticos e soluções de caráter institucional, além da tendência a um tratamento mais técnico e especializado dos conflitos. Notamos, por exemplo, o modo como o Ministério da Saúde elaborou, no período, uma "agenda SUS" e colocou assessores graduados para debater com os conselheiros cada ponto destacado. São exemplos de acordos em torno de questões conflitivas a apreciação de resoluções da comissão tripartite, reajustes na tabela de pagamentos, formação de inúmeros grupos temáticos, organização da X Conferência Nacional de Saúde, elaboração da Norma Operacional Básica-SUS de 1996, pleito pela aprovação da Contribuição Provisória de Movimentação Financeira (CPMF) pelo Congresso Nacional, entre outros. A propensão observada à pactuação não oculta, por outro lado, os conflitos que transparecem nas propostas e fal as de conseIheiros, especialmente em torno do "descaso do governo com a saúde", da "falta de recursos para atender a população", das denúncias de fraudes e de atendimento de baixa qualidade. A tendência à pactuação deve, portanto, ser entendida como um compromisso mútuo de institucional ização das soluções propostas e não como de superação de divergências.

No caso do modelo de vocalização política, o seu perfil é mais imediatamente percebido, na medida em que os conflitos, além da alta intensidade discursiva, criam situações de ruptura iminente no ambiente instituído coletivamente. Não apontamos um conselho em especial, na medida em que a maioria dos observados se aproxima deste padrão. Neste caso, muitas ações governamentais ou societárias se concentram em denunciar intenções e interesses supostamente não explicitados nos discursos dos interlocutores, e muitas das propostas elaboradas não são passíveis de aceitação e implementação imediata. De certa forma, tais comportamentos podem ser encontrados no modelo anterior, porém o fator de diferenciação está justamente no grau de institucionalização dos conflitos. Em conselhos onde predomina a vocalização política, há uma sobrecarga de demandas ao sistema instituído que afeta a dinâmica de pactuação e de busca de consensos. Isto faz com que os temas da agenda sanitária sejam freqüentemente tratados por ações extra-institucionais, fora daquele ambiente. A institucionalização deve ser entendida pelo predomínio de diagnósticos, soluções e ações 
estabelecidas no âmbito de organismos normativos oficiais e dentro de parâmetros técnicos e político-discricionários pertencentes à política setorial, pelo que implica a absorção dos grupos em esferas do estado e a aceitação pelos governantes da legitimidade dos representantes dos grupos sociais.

Estes modelos não são evolutivos ou causais. Os conselhos onde predomina a vocalização política decorrem de situações diversas, tais como as que resultam de resistências governamentais à sua implantação ou onde as forças político-partidárias, sindicatos, associações de moradores, têm intensa atividade. $\mathrm{O}$ caráter instável destes arranjos não decorre de uma necessária fraqueza dos grupos de interesses (podem representar inclusive sua força política), mas sim dos conflitos aí gerados, que tendem a promover fluxos e refluxos na atividade do conselho e momentos de retração na absorção de suas resoluções como agenda pública. A redução da instabilidade é obtida pelo estabelecimento de acordos e implementação governamental de decisões políticas, o que pode acarretar a emergência de um padrão mais estável de pactuação, que pode retornar ao anterior em função das demandas aí colocadas e de alterações na agenda de grupos de interesses relevantes.

O modelo de pactuação implica certa autolimitação de programas dos grupos de interesses e da esfera governamental, seja por cálculos estratégicos ou pelo estabel ecimento de hegemonias mais intensas, em prol de uma gestão compartilhada e consensual da política pública. Neste caso, os fatores estabilizadores podem originar-se de situações diversas, desde dominação política, até uma percepção coletiva de equilíbrio de forças entre os grupos de interesses. No caso da hegemonia política, a situação mais comumente encontrada é a conhecida prefeiturização do conselho, em que a dominação política exercida pelo executivo decorre de relações patrimonialistas ou de algum tipo de liderança carismática. Na outra situação, grupos de interesses articulados à dinâmica do consel ho percebem vantagens, em termos de eficiência na viabilização de seu programa, em praticar a autolimitação em prol de maior comprometimento das partes com as decisões políticas.

A definição destes modelos dá-se conforme as questões de ordem teórica anteriormente levantadas e que destacam a relevância do Estado na definição de instâncias decisórias, do status de representação dos grupos de interesse e da própria agenda política. A oportunidade dos estudos comparados advém da rápida multiplicação dos conselhos de saúde. NaTabela 1, observa-se em todas as unidades da federação a presença de conselhos estaduais de saúde. Chamamos a atenção para a coluna dos municípios considerados habilitados, por tal implicar a existência de conselho municipal de saúde. Podemos observar que mais da metade dos municípios de dez estados possuem conselhos, destacando-se a situação de alguns mais populosos, como M inas Gerais (91,9\%), São Paulo (51,0\%), Paraná (85,9\%) e Santa Catarina (68,4\%). O total de municípios existentes no Brasil em setembro de 1995 era de 4.974, dos quais 2.695 (54,2 \%) estavam habilitados em algum dos três níveis de gestão previstos pela NOB-93: 2.058 em gestão incipiente, 593 em parcial e 44 em semiplena. Sabemos ainda que o processo de habilitação continua em ritmo acelerado. Trata-se de evidência da importância destes arranjos para a política setorial.

Alguns eventos possíveis, em aberto, podem favorecer determinados modelos. Em caso de escassez exagerada de recursos ou de vitórias políticas expressivas de grupos conservadores, por exemplo, um certo esvaziamento nas decisões pode determinar o predomínio da prática de denúncias políticas no interior dos conselhos. A pactuação política pode prevalecer em casos de vitórias eleitorais de partidos políticos de esquerda, na medida em que estes propugnam reformas democratizantes sobre os arranjos construídos pelo regime militar pós-64. Além disso, a adesão de grupos sociais poderia favorecer sua legitimação política nos confrontos com o neoconservadorismo. Mas estas vinculações não são necessárias e podemos observar situações de conselhos funcionando em municípios governados por partidos conservadores. De qualquer forma, estes são apenas exemplos de possibilidades a serem mais bem estudadas.

Do ponto de vista das relações entre Estado e sociedade civil, os consel hos de saúde e o temário da participação social não representam por si mudanças estruturais na sociedade. A participação social pode resultar na absorção destes organismos por agências do Estado ou, pelo contrário, na sua autonomização na sociedade civil enquanto movimento social. A ampliação do espectro destes organismos multipartites em termos de decisões relevantes não é, contudo, um processo simples. Como aponta Costa (1994), atores relevantes a este processo, como muitos sindicatos de trabalhadores industriais, de empresas estatais e de funcionários públicos, auto-excluíram-se destas barganhas e aderiram aos seguros-saúde, obtendo cestas de produtos amplamente com- 
Tabela 1

O rganismos colegiados do SUS por Unidade da Federação.

\begin{tabular}{|c|c|c|c|c|c|}
\hline UF & $\begin{array}{c}\text { Conselho Estadual } \\
\text { de Saúde }\end{array}$ & $\begin{array}{l}\text { Bipartite } \\
\text { Estadual }\end{array}$ & $\begin{array}{l}\text { Fundo Estadual } \\
\text { de Saúde }\end{array}$ & $\begin{array}{c}\text { Municípios Habilitados } \\
\text { NOB/93 }\end{array}$ & $\begin{array}{c}\text { Programação Financeira } \\
\text { na Bipartite }\end{array}$ \\
\hline$A C$ & Sim & Sim & Não & $4(18,2 \%)$ & Não \\
\hline AP & Sim & Sim & - & - & - \\
\hline$A M$ & Sim & Sim & - & - & - \\
\hline PA & Sim & Sim & Não & $18(14,0 \%)$ & Sim \\
\hline RO & Sim & Sim & Não & $10(25 \%)$ & Sim \\
\hline $\mathrm{RR}$ & Sim & Sim & Não & - & Sim \\
\hline TO & Sim & Sim & Sim & $6(4,9 \%)$ & Sim \\
\hline$A L$ & Sim & Sim & - & $58(58 \%)$ & - \\
\hline BA & Sim & Sim & Sim & $132(31,8 \%)$ & Sim \\
\hline$C E$ & Sim & Sim & Sim & $135(73,4 \%)$ & Sim \\
\hline MA & Sim & Sim & Sim & 27 (19,9 \%) & Sim \\
\hline PB & Sim & Sim & Sim & $76(44,4 \%)$ & Sim \\
\hline PE & $\operatorname{Sim}$ & Sim & Sim & $84(47,5 \%)$ & Sim \\
\hline $\mathrm{PI}$ & Sim & Sim & - & $96(64,8 \%)$ & Sim \\
\hline RN & Sim & Sim & Sim & $119(78,3 \%)$ & Sim \\
\hline SE & $\operatorname{Sim}$ & Sim & Não & $10(13,3 \%)$ & Sim \\
\hline DF & Sim & - & Sim & - & - \\
\hline GO & Sim & Sim & - & $97(41,8 \%)$ & - \\
\hline MT & Sim & Sim & - & $58(49,6 \%)$ & Sim \\
\hline MS & $\operatorname{Sim}$ & $\operatorname{Sim}$ & $\operatorname{Sim}$ & $41(53,2 \%)$ & Sim \\
\hline ES & $\operatorname{Sim}$ & $\operatorname{Sim}$ & Não & $50(70,4 \%)$ & - \\
\hline MG & Sim & Sim & Não & $695(91,9 \%)$ & Sim \\
\hline $\mathrm{RJ}$ & Sim & Sim & Sim & $22(27,2 \%)$ & - \\
\hline $\mathrm{SP}$ & $\operatorname{Sim}$ & $\operatorname{Sim}$ & Sim & $319(51,0 \%)$ & Sim \\
\hline PR & $\operatorname{Sim}$ & Sim & Não & $319(85,9 \%)$ & Sim \\
\hline RS & Sim & Sim & Sim & $141(33,2 \%)$ & Sim \\
\hline SC & Sim & Sim & Sim & $178(68,4 \%)$ & Sim \\
\hline
\end{tabular}

Fonte: Tabela construída com base no documento Brasil, SAS/Ministério da Saúde, Segundo Relatório sobre o Processo de O rganização da Gestão da Assistência à Saúde. Setembro - 1995.

pensatórias por referência ao racionamento observado no SUS. Assinale-se, aliás, que grande parte destes sindicatos compõe a base política da esquerda no Brasil. Somem-se a isto as dificuldades de incorporação dos setores empresariais aos conselhos de saúde, seja por motivações políticas locais, ou pela relação direta que muitos deles estabelecem com governos em geral.

Em resumo, o estabelecimento de arranjos de caráter neocorporativo, estimulados pela Constituição de 1988 e pelas estratégias políticas da esquerda, ganhou expressão no setor saúde, congregando organizações de caráter nacional relevantes para a política setorial (Ribeiro, 1993; 1994). Esta lógica pode ser observada em outras políticas, como na seguridade social (pelo Conselho Nacional da Seguridade Social), na política assistencial (pelo Conselho da Comunidade Solidária). Além disso, propos- tas episódicas do governo Fernando Henrique Cardoso de acordos com centrais sindicais, movimento dos sem-terra, de curta duração até o momento, revelam tímidas tentativas de reproduzir no cenário brasileiro os pactos sociais que se tornaram corriqueiros no cenário europeu quando da hegemonia dos partidos social-democratas.

Pactuação intergovernamental no SUS: as comissões intergestores

A proliferação de organismos colegiados no SUS pode ser evidenciada pelas comissões intergestores. Estas comissões atuam como instâncias executivas dos conselhos de saúde, mas a sua composição exclusivamente governamental promove grande agilidade decisória, além da influência relevante da tecno-burocra- 
cia estatal em seu processo decisório. O dinamismo observado em alguns estados acarreta, inclusive, certo conflito de competências com os próprios conselhos, inclusive entre a tripartite e o consel ho nacional. Apesar dos conseIhos configurarem arranjos de controle societário, conforme definição constitucional, na verdade expressam uma extensão do Estado junto à sociedade civil. A possibilidade das comissões intergestores, de caráter intergovernamental, atuarem em sintonia com os conselhos amplia o caráter institucional que eles possuem, porém estas comissões têm apresentado uma dinâmica decisória caracterizada menos por uma subordinação formal aos conselhos de saúde e mais por um forte tensionamento da política pela especialização técnica adquirida por seus componentes.

Na esteira de um processo político no qual são fortal ecidas posições municipalistas, e em seguimento às resoluções da IX Conferência Nacional de Saúde, o Ministro da Saúde Jamil Haddad emitiu a Portaria 545, de 20 de maio de 1993, estabelecendo a Norma Operacional Básica - SUS 01/ 93 (MS, 1993). A NOB-93 foi um marco na política sanitária dos anos 90 e definiu mecanismos de transferência de recursos, estabelecendo níveis progressivos de gestão local do SUS. A aliança entre setores do executivo federal, mais notadamente a SAS/ MS, e organizações relevantes à política de saúde (Conasems e Conass) mostra-se evidente - a NOB93 é uma regulamentação estabelecida a partir do documento “Descentralização das ações e serviços de saúde: a ousadia de cumprir e fazer cumprir a lei" do Conselho Nacional de Saúde de abril de 1993, consagrando teses de descentralização gerencial. Embora não tenha sido bem sucedida na agilização de transferências financeiras, devido a contestações da área econômica do Governo Itamar Franco quanto à regulação do sistema, a NOB-93 estabeleceu parâmetros de ordenamento administrativo na forma de níveis de gestão estadual e municipal, e reforçou a pactuação através das comissões intergestores. Os itens centrais podem ser resumidos como a seguir.

Um deles diz respeito ao estabelecimento de padrões evolutivos de autonomia gerencial de estados e municípios. Pela fórmula criada, o SUS teria a sua execução descentralizada por níveis de gestão, começando pela incipiente, seguida pela parcial e culminando pela semiplena. A progressão decorre do tipo de comprometimento assumido quanto à organização da assistência à saúde, sua adequação a parâmetros preestabelecidos de programação e reflete-se em maior autonomia local para dispor de recursos. Na prática, a gestão parcial não gerou maiores conseqüências financeiras, porém a gestão semiplena representa para o município o recebimento dos recursos SUS na forma de pré-pagamento por estimativa de consumo e maior liberdade na sua aplicação. Esta modalidade de gestão tem se multiplicado. Como vemos na Tabela 1, congregava 44 municípios em setembro de 1995 e atual mente existe um fluxo crescente de enquadramentos que elevou este número para a centena. Estudos técnicos devem ser ainda produzidos para avaliar o impacto desta inovação para o desenvolvimento da rede e desempenho gerencial destes municípios.

Outro item, este mais bem-sucedido, refere-se às comissões intergestores aqui discutidas. Diz a NOB-93: “O gerenciamento do processo de descentralização no SUS (...) tem como eixo a prática do planejamento integrado em cada esfera de governo e como foros de negociação e deliberação as Comissões Intergestores e os Consel hos de Saúde ...". Neste caso, a inovação diz respeito às comissões instituídas atualmente em todos os estados e no plano nacional, como mostra a Tabela 1. A comissão intergestores tripartite tem caráter paritário, estando representados o Ministério da Saúde, o Conass e o Conasems e "tem por finalidade assistir o Ministério da Saúde na elaboração de propostas para a implantação e operacionalização do SUS, submetendo-se ao poder deliberativo e fiscalizador do Consel ho Nacional de Saúde". No âmbito estadual, as comissões intergestores bipartite são formadas por dirigentes da secretaria estadual de saúde e o órgão de representação dos secretários municipais de saúde do estado, "sendo a instância privilegiada de negociação e decisão quanto aos aspectos operacionais do SUS (...) cujas definições e propostas deverão ser referendadas ou aprovadas pelo respectivo consel ho estadual ...".

A institucional ização dos conflitos através dos conselhos de saúde foi fortalecida através das comissões intergestores, em função da maior agilidade observada no processo decisório, modificando o arcabouço burocrático do sistema, em decorrência de um certo grau de autonomização observado nestes organismos intergovernamentais.

Uma comparação entre tais dinâmicas pode ser esboçada. Nos conselhos de saúde, como apontado, o modelo gravita entre a vocalização e a pactuação política; nas comissões intergestores, o processo de institucionalização dos conflitos encontra-se bastante adiantado em função basicamente de dois fatos. O primeiro deles refere-se à relação estabelecida en- 
tre o Ministério da Saúde e a tripartite, portanto, entre o governo federal e organizações nacionais como Conass e Conasems. Neste caso, observa-se uma articulação estável entre técnicos de diferentes esferas. O segundo, que tem revelado alto grau de redução de conflitos e pactuação política, refere-se às bipartites estaduais. Aqui observou-se um importante deslocamento de competências anteriormente concentradas nas secretarias estaduais de saúde, que passaram a ser divididas com as secretarias municipais, ampliando-se o leque de consultas.

A manutenção deste arranjo depende, no entanto, da articulação entre a dinâmica das bipartites com a dos conselhos estaduais de saúde em torno das competências administrativas. Uma observação preliminar aponta para a existência de um interesse do MS em estimular estes organismos colegiados e uma aceitação, em geral, pelos estados em dividir competências técnicas e políticas com representantes dos municípios. Isto nos parece uma convergência de interesses suficientemente sólida para a preservação destes organismos.

Este arcabouço, entretanto, tem se mostrado eficiente, na medida em que a revisão da Norma Operacional Básica do SU S para 1996 acabou por fortalecer estes organismos colegiados e buscou normatizar as suas relações com os conselhos de saúde, como diz seu texto: "As conclusões das negociações pactuadas na CIT e na CIB são formalizadas em ato próprio do gestor respectivo. Aquelas referentes a matérias de competência dos conselhos de saúde, definidas por força da Lei Orgânica, desta NOB ou de resolução específica dos respectivos conselhos são submetidas previamente a estes para aprovação. As demais resoluções devem ser encaminhadas, no prazo máximo de 15 dias decorridos de sua publicação, para conhecimento, avaliação e eventual recurso da parte que se julgar prejudicada, inclusive no que se refere à habilitação dos estados e municípios às condições de gestão desta Norma" (MS, 1996). As condições de gestão às quais se reporta a NOB-SUS/ 96 representam um reordenamento com relação ao anteriormente estabelecido, convergindo para duas situações definidas como de gestão plena: a da atenção básica e a do sistema municipal. São explicitados mecanismos de ordenamento da administração pública centrados na lógica da pactuação política, por sua vez submetida ao crivo dos parâmetros técnicos. Estes níveis evoluem para a desejada situação plena de gestão do sistema local de saúde.

\section{Considerações finais}

Buscamos apontar neste artigo algumas inovações políticas observadas na política de saúde no Brasil, nos anos 90. Assinalamos que o entendimento mais adequado da dinâmica de formulação e de tomada de decisões depende da compreensão das relações instituídas entre Estado e sociedade civil e os mecanismos de constituição e atuação dos grupos de interesses. Chamamos a atenção para a instituição de instâncias compartilhadas de decisão, pelo que podemos especular acerca da sua autonomização como "governos privados", por um lado, ou da incorporação de grupos sociais a interesses estruturados no âmbito do Estado. Esta dialética da organização social, traduzida no conflito insuperado entre Estado e sociedade civil, pode ser apreendida pelo estudo da política de saúde e seus arranjos recentes no Brasil, especialmente na década de 90.

Ao se conferir relevância aos grupos de interesses na política pública, decorre a necessidade de estudar os próprios mecanismos de constituição de interesses comuns entre indivíduos e de delegação de poderes de representação. As ciências sociais oferecem ferramentas importantes para a área da saúde. Os estudos sobre escolha racional e a ação coletiva lidam com a necessidade de explicar a emergência de decisões al truístas, orientadas por normas sociais para além do puro interesse individual, ea própria constituição de bens públicos, quando as decisões individuais de caronear (free-rider), não cooperativas, expressam o meIhor resultado individual. As teorizações acerca dos dilemas apontados nestes "jogos" têm freqüentado a literatura das ciências sociais, representando tanto a crise observada no marxismo estruturalista, como a importação de esquemas analíticos da economia, disciplina colocada no centro dinâmico das explicações sociais contemporâneas. À parte a relevância do debate de caráter epistemológico, interessanos apontar a oportunidade de utilizar instrumental analítico diferenciado por referência aos usualmente empregados na área da saúde. Os novos organismos colegiados assinalados neste artigo representam uma base empírica bastante rica para se avançar na compreensão do próprio Estado enquanto matriz distinta do mercado como elemento de regulação da sociedade. 


\section{Referências}

CARVALho, A. I., 1995. Consel hos de Saúde no Brasil: Participação Cidadã e Controle Social. Rio de Janeiro: Instituto Brasileiro de Administração Municipal/FASE.

COSTA, N. R., 1994. Políticas públicas, direitos e interesses: reforma sanitária e organização sindical no Brasil. Revista de Administração Pública, 28: 5-17.

ELSTER, J., 1989. The Cement of Society - A Study of Social Order. Cambridge: Cambridge University Press.

ELSTER, J., 1994. Peças e Engrenagens das Ciências Sociais. Rio de Janeiro: Relume-Dumará.

FAVERET FILHO, P. \& OLIVEIRA, P. J., 1989. A Universalização Excludente- Reflexões sobre as Tendências do Sistema de Saúde. Rio de Janeiro: Instituto de Economia Industrial/ Universidade Federal do Rio de Janeiro.

HABERMAS, J., 1968. Técnica e Ciência como “Ideologia". Lisboa: Edições 70.

HABERMAS, J., 1994. A Crise de Legitimação no Capitalismo Tardio. 2a ed. Rio de Janeiro: Tempo Brasileiro.

IANNI, O., 1986. Estado ePlanejamento Econômico no Brasil. 4a ed. Rio de Janeiro: Civilização Brasileira.

MELAMED, C. \& RIBEIRO, J. M., 1995. O inquérito civil público sobre a saúde. Conjuntura e Saúde, 20:17-21.

MENDES-GONÇALVES, R. B.; SCHRAIBER, L. B. \& NEMES, M. I. B., 1990. Seis teses sobre a ação programática em saúde. In: Programação em Saúde Hoje(L. B. Schraiber, org.), pp. 37-63. São Paulo: Hucitec.

MERHY, E. E., 1992. A Saúde Pública como Política: Um Estudo de Formuladores de Políticas. São Paulo: Hucitec.

MS (Ministério da Saúde), 1993. Descentralização das Ações eServiços de Saúde: A Ousadia deCumprir e Fazer Cumprir a Lei. Brasília: MS.
MS (Ministério da Saúde), 1996. Norma Operacional Básica do SUS - NOB-SUS 01/96: gestão plena com responsabilidade pela saúde do cidadão. Diário Oficial da União, 06 de novembro de 1996. p. 22.932-22.940.

OFFE, C., 1984. Problemas Estruturais do Estado Capitalista. Rio de Janeiro: Tempo Brasileiro.

OFFE, C., 1989. Capitalismo Desorganizado - Transformações Contemporâneas do Trabalho e da Política. São Paulo: Brasiliense.

RIBEIRO, J. M., 1993. Arranjos neocorporativos e defesa de interesses dos médicos. Cadernos de SaúdePública, 9:5-20.

RIBEIRO, J. M., 1994. O SUS e o desafio neocorporativo. Saúdeem Debate, 44:4-8.

RIBEIRO, J. M., 1996. Estruturas tecno-burocráticas e instâncias colegiadas no SUS: uma abordagem dos fundamentos da política setorial. In: Política de Saúde e Inovação Institucional: Uma Agenda para os Anos 90 (N. R. Costa \& J. M. Ribeiro, orgs.), pp.51-68. Rio de Janeiro: Secretaria de Desenvolvimento Educacional/Escola Nacional de Saúde Pública.

SCHIMITTER, P., 1979. Still de century of corporatism? In: Trends Toward Corporatist Intermediation (P. C. Schmitter \& G. Lehmbruch, eds.), pp. 7-52. London: Sage.

SCHRAIBER, L. B., 1993. O Médico e seu Trabalho: Limites da Liberdade. São Paulo: Hucitec.

SOUZA-CAM POS, G. W., 1988. Os Médicos ea Política deSaúde: Entrea Estatização e o Empresariamento - A Defesa da Prática Liberal da Medicina. São Paulo: Hucitec.

SOUZA-SANTOS, B., 1995. Pela Mão deAlice- O Social eo Político na Pós-Modernidade. São Paulo: Cortez Editora.

VAITSM AN, J., 1989. Corporativismo: notas para sua aplicação no campo da saúde. In: Reforma Sanitária: Em Busca de uma Teoria (S. Fleury, org.), pp. 139-156, São Paulo: Cortez.

WRIGHT, E. O.; LEVINE, A. \& SOBER, E., 1993. Reconstruindo o Marxismo - Ensaios Sobre a Explicação eTeoria da História. Petrópolis: Vozes. 